\title{
The construction materials and static-structural aspects of the Budello tower (Teulada, southwest Sardinia, Italy)
}

\author{
Stefano Columbu a , Gian Matteo F. Picchizzolu ${ }^{\text {b }}$, Antonio Cazzani ${ }^{\text {c }}$ \\ a Dipartimento di Scienze Chimiche e Geologiche - Università degli Studi di Cagliari, Italy, columbus@unica.it \\ ${ }^{\mathrm{b}}$ Freelance engineer, Cagliari, Italy, studio.picchizzolu@gmail.com \\ c Dipartimento di Ingegneria Civile, Ambientale e Architettura - Università degli Studi di Cagliari, Cagliari, Italy, \\ antonio.cazzani@unica.it
}

\begin{abstract}
The Budello tower is located on a slight promontory from which it dominates the entire bay of Teulada and the towers of Sant'Isidoro, Pixinni, Malfatano and Porto Scudo. The tower, built in 1601 with irregular ashlars of local stones (mainly of magmatic-intrusive origin), has a truncated cone shape, an external diameter of 10,2 $\mathrm{m}$ and a height of $11,80 \mathrm{~m}$. Inside it consists of a single room, with a domed vault and a central pillar, equipped with a embrasure, a fireplace, a trap door in the cistern, and a staircase, from which the square of arms was accessed. It was a torre de armas garrisoned by: 1 commander (in 1603), 1 artilleryman and 4 soldiers (1767), 1 artilleryman and 3 soldiers (1801), 1 artilleryman and 4 soldiers (1812).

Although it underwent several restorations, documented as early as the years 1617-1619, the tower remained generally in good condition until the period 1763-1784, in which new restoration works were carried out including the closure of the parade ground with a classic parapet with gunboats and battlements. Other restoration works are carried out in 1808, 1819 and 1840 . The tower remained in operation until 1843. Like all the other coastal fortifications, it was then definitively demilitarized with the Regio Decreto of 25 April 1867.

Specific objectives of the research are the petrographic and physical-mechanical analysis of the stones and ancient mortars used in the construction of the tower, the structural analysis of the building and related geometric-constructive characteristics. The final intention is to understand the decay processes taking place on the tower both in terms of materials and static-structural aspects, and to envisage possible restoration interventions to be implemented aimed at its conservation.
\end{abstract}

Keywords: Stone, mortar, petrography, physical-mechanical features.

\section{Introduction and aims of the research}

The Budello tower (Fig. 1), which is part of the larger Spanish defensive system in Sardinia, is a defensive post built in 1601 by the entrepreneur from Cagliari, Pietro Porta, already owner of the Piscinnì tonnara (the tuna catching plant). It is built in the municipality of Teulada Cagliari $\left(38^{\circ}\right.$ $55^{\prime} 55.57^{\prime \prime} \mathrm{N}, 8^{\circ} 43^{\prime} 22.15^{\prime \prime} \mathrm{E}$ ) and in particular, it was inaugurated in December 1601 and decommissioned in March 1843, even if the definitive demilitarization took place in April 1867 (Royal Decree of April 25, 1867, which concerns the demilitarization of all the other coastal fortifications). It stands near the homonymous beach at an altitude of $12 \mathrm{~m}$ (Montaldo 1992); 
from the seventeenth century historical documents date it to 1603 with the name "torre del Budello", then take the name "Teulada tower" between 1763 and 1773 and subsequently "Saint Joan del Budel" between the seventeenth and eighteenth centuries.

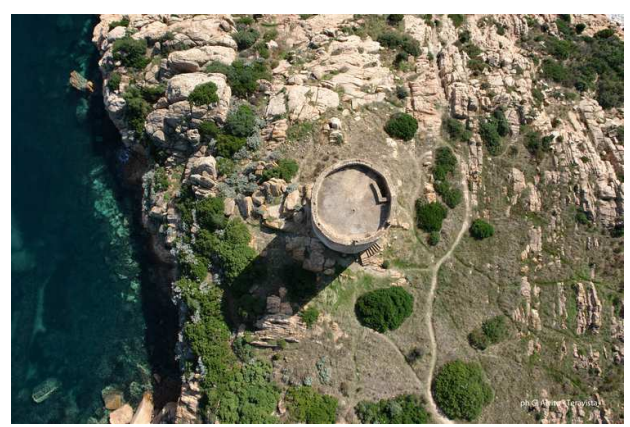

Fig. 1. Aerial view of Budello tower.

The tower, although built in 1601-1603, underwent several restoration interventions, also for its position close to the coast, in detail between 1617 and 1619, and then in the years 1720, 1763, 1784 and 2000. The parade ground was closed by classic parapet with gunboats and battlements are to be classified as torre senzillas, that is, as a medium-sized tower equipped with two cannons and a pusher being a torre de armas. Between 1801 and 1812 it counted on a garrison composed of a gunner and three or four soldiers.

\subsection{Historical context}

The provision of 1502 orders the expulsion of the Moors from Spain. The expulsion has determined the alliance between the Saracens and the Berbers of North Africa. Consequently in the following decades the coasts of Sardinia and in particular those of the south were affected by continuous assaults by the Barbary corsairs who followed one another for most of the sixteenth century until in 1570, the Crown of Spain intervened by planning a plan of coastal defence also through the construction of coastal towers built in strategic points of the coast, already in $\mathbf{1 5 8 0}$ there were thirty towers built (Guidetti, 1989). In 1581 Philip II of Spain established the Royal Tower Administration to organize and manage the entire Sardinian coastal defence system (Mele, 2000). The coastal defensive system consisted of three models of towers (Montaldo, 1992) (Fig. 2):

- Gagliarde, it was structured for a heavy defence, equipped with four large-caliber cannons;

- Senzillas, of medium size for light defence, it had two medium-caliber cannons, a pusher and three caliber rifles, two pusher and five rifles;

- Torrezillas, outposts of sighting and it had two rifles and a pusher.

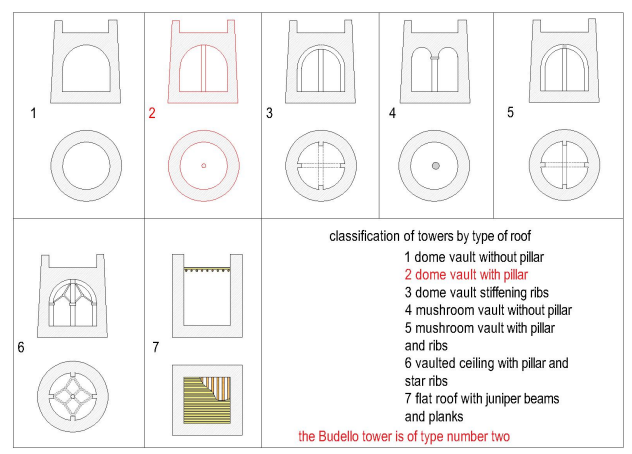

Fig. 2. Tower construction models; the Budello tower model is two type.

The Sardinian coastal defence system remained operational until 1867 , the year in which a royal decree decreed its abolition for military use. In reality, not all the towers were abandoned and some, which passed to the Ministry of Finance, underwent substantial changes to adapt them to customs. Others, especially in the bay of La Maddalena, were turned into batteries for strategic control of the Mediterranean sea at the end of the nineteenth century, a function that they maintained even after the First World War. During the second conflict, many towers of the island were converted as optical sighting points. The definitive disposal of the coastal towers as a defensive system was implemented only in 1989, in conjunction with State-Region agreement.

\subsection{Architectural features of Budello tower}

Built on a rocky plateau at $12 \mathrm{~m}$ of altitude near the coastline, the tower has a conical shape with a base diameter of 10,2 $\mathrm{m}$ and a height of 11,80 
m. It is accessible from a passage currently walled placed at about $1,80 \mathrm{~m}$ from the current ground level served by a stone staircase of posthumous period to the building of the tower.

The tower has a circular section and a vaulted roof supported by a central pillar (Figs. 3 and 4). Along the internal perimeter there is the stairs for access to the roof terrace. Inside there is a room with a fireplace, a skylight and two slits.

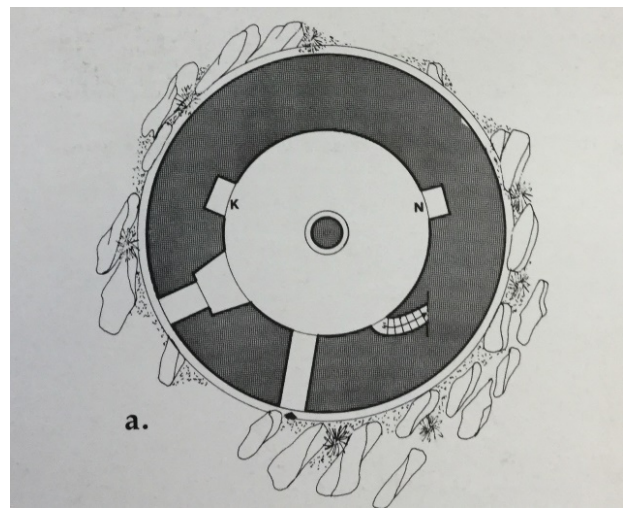

Fig. 3. Plan of the Budello Tower.

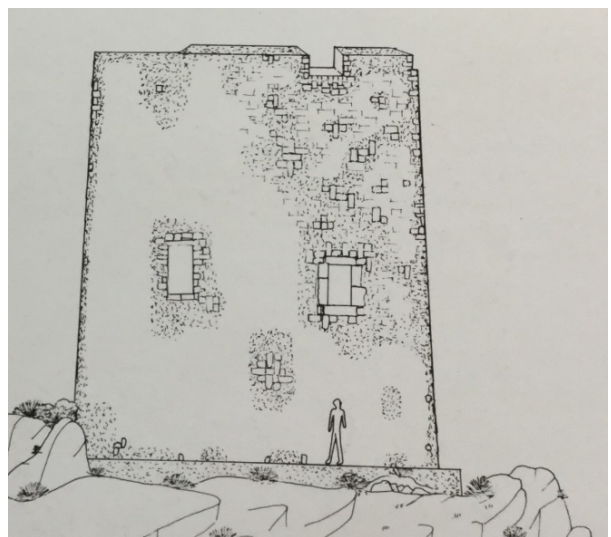

Fig. 4. Front elevation (1984).

The masonry wall in granitoid material found in situ is irregularly, it is composed of a mix of lime and small stones. Internal staircase is inserted inside the perimeter load-bearing masonry as in the plan (Fig. 3) and the axonometric representation (Fig. 4). The stairwell (Figs. 5 and 6) inserted inside the masonry, has the vault made up by a juniper wood deck, typical of local arboreal essence.

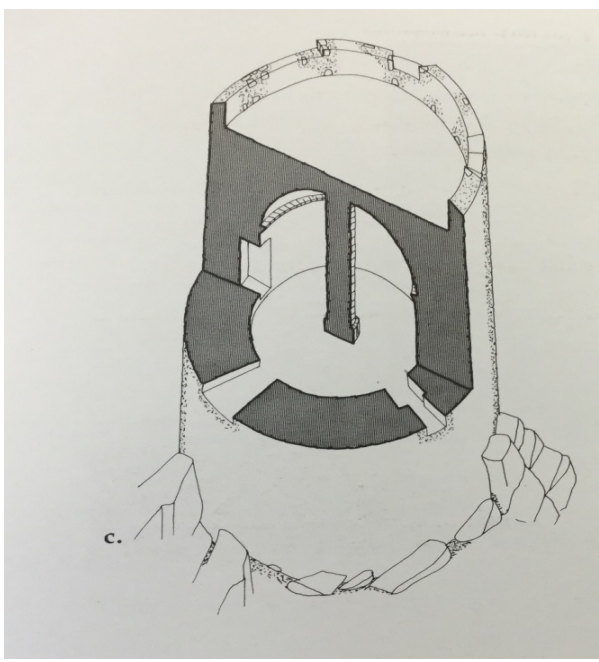

Fig. 5. Budello Tower axonometric representation.

\subsection{Objects of the research}

The research aims to study the architectural morphological aspects, belongs to the senzillas category, characterized by a central column in stone material (that supports the vault surmounted by the roof), a staircase grafted into the revolving perimeter (Fig. 6), a conical wall structure.

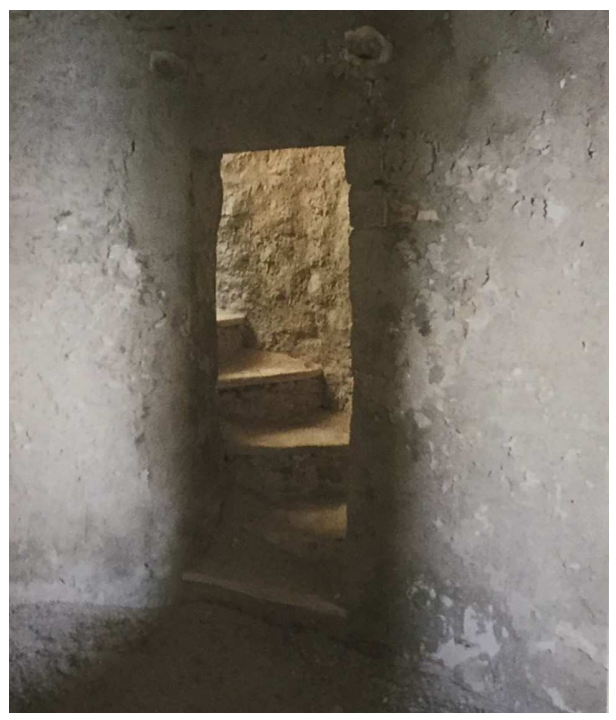

Fig. 6. The staircase of Budello tower. 
The construction material features and their decay processes also are the object of analysis, to know the petrographic and physical characteristics of stones that constitutes the base and the masonry of the tower, as well as all the internal structural elements. Even the external finishing mortars that appear in several layers, due to different maintenance interventions over time, and the bedding mortars inside the wall, are the aims of this study.

\section{Materials and methods}

The methodological approach adopted to the study of constructive materials and structural aspects (in agreement with Columbu, et al., 2015b) is based on different strategic intervention lines: evaluation of the architectural and structural aspects of the tower with dating of the tower typological classification, analysis of the construction technique, description of construction phases of the tower, lithological mapping and analysis of main petrographic and mineralogical features of stones and ancient mortars.

The lithoid materials (rocks, ancient mortars) used in the construction of the tower were studied and analysed substantially on a macroscopic basis. The study was addressed in this first preliminary work, in characterizing only the materials recognizable outside the tower structure. The recognition of the lithologies and the characterization of textural and structural aspects were made using an portable optical microscope in reflected light, which made it possible in some cases to recognize also the mineralogical phases through the study of the crystalline habitus.

The study of mortars was carried out subdividing them into: bedding mortar of stone ashlars (not clearly observable in situ), render mortars of wall and plasters. The render mortars are used to close the centimetre space between the stone ashlars and to prepare the substrate for the next finishing layer of plaster. From the macroscopic examination it was not possible to understand whether they themselves also function as bedding mortars for the stone ashlars. An adequate and statistically significant sampling and study of materials (currently not yet executed) could certainly resolve these constructive and stone- compositional aspects. The plaster mortars represent the external finish that in the past was completely covering the irregular truncatedconical wall of the tower.

The macroscopic analysis of the entire external wall of the tower has also allowed the mapping and definition of the forms of degradation (e.g. exfoliation, flaking, alveolation, salt crystallization, etc.) and to understand how the alteration processes of material evolve.

\section{Results and discussion}

\subsection{Construction phases of tower and related dimensional/geometric aspects of structure}

The tower, built in 1601 to a design by the military engineers of the Crown of Spain, refers to the typology of the Senzillas tower.

The tower masonry consists of irregular medium-sized stone ashlars found in situ, together lime mortars and smaller elements inserted to reduce the presence of voids. There is the presence of stone elements of greater regularity, near the openings, ashlars with joints always bedded with lime mortars. The courses are with stone material arranged in a predominantly horizontal manner. The construction of the staircase inserted inside the circular wall face occurred simultaneously with the building of the same masonry that being tapered, outside with an angle of about 5 degrees. The central pillar supports the vault and the overlying roof. The tower (with a diameter about 10,2 $\mathrm{m}$ ) has a circumference of $33 \mathrm{~m}$.

It should be noted that near the openings the wall curve changes, giving these wall portions of the tower a pseudo-flat surface. It should be remembered that the tower has undergone various maintenance operations in the southern part, the most degraded and exposed to sea water have involved a heavy restoration of the wall. It is not excluded that these interventions have modified the external geometric profile of the tower. 


\subsection{Petrographic features of geomaterials}

\subsubsection{Stones}

The tower, located on a rocky promontory weakly emerging with respect to the surrounding territory (Fig. 7), it was mainly built with ashlars (Fig. 8) consisting of local granitoid rocks (about $90 \%$ ) belonging to the plutonic complex of the Carboniferous Superior - Permiano, represented in the area near the tower by equigranular leucogranites and equigranular granodiorites. Occasionally we find the presence of other magmatic rocks belonging to the dikes associated with the plutonic complex outcropping in the area, and sedimentary rocks (sandstones, calcarenites).

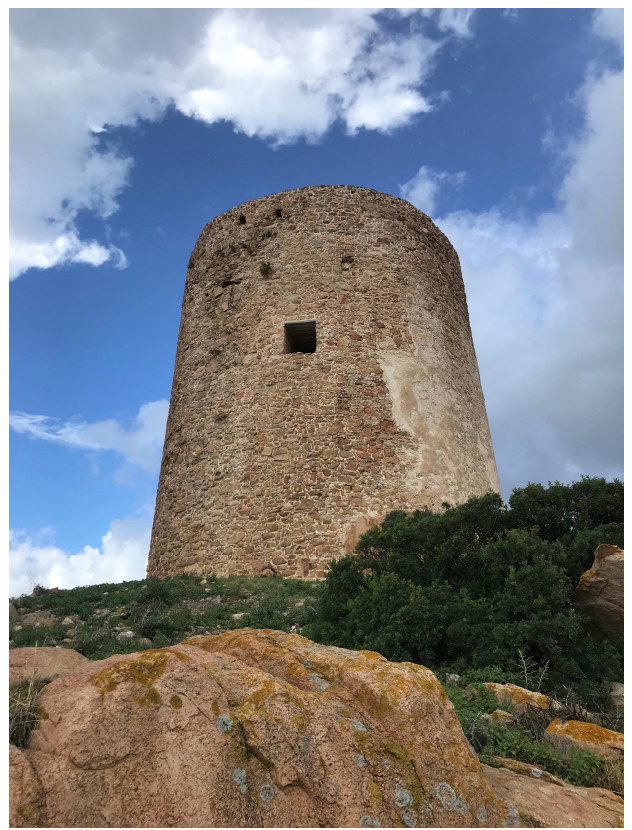

Fig. 7. Budello tower from south-east view.

In the jambs of the wall openings were used granitoid rock elements (at the time of dubious origin), together with occasional other rocks of various kinds and origins.

The granitoid rocks used in the tower masonry were quarried in the area in front of the building (Fig. 9). In fact, in the area surrounding the tower there is the presence of small intrusive rock plateaus, presumably referable to the original quarry planes. These are observed both west and north of the tower. In these two sectors, especially in the northern one, today it is still possible to see the traces of working for the extraction of the stone blocks or ashlars, represented by chipping holes generated by the chisels. The extraction method was very simple, because it exploited the natural conformation of the outcropping rock: the stone ashlars were derived using the cracking / fracturing present in the rock outcrop, characterized by two sub-orthogonal fissuring orientations.

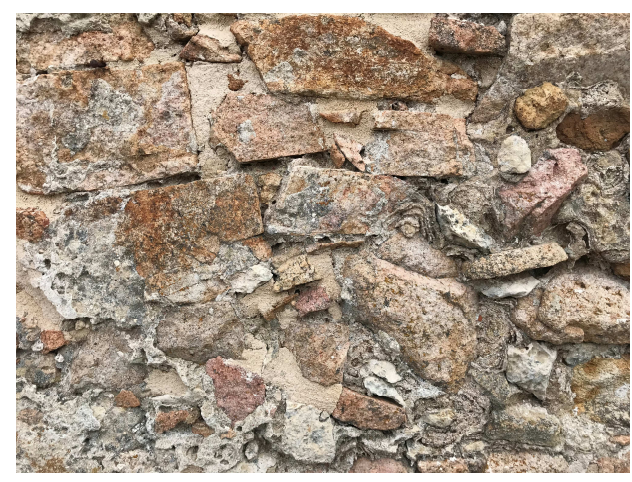

Fig. 8. Stone irregular ashlars of north side tower wall.

The stone ashlars of the truncated-conical structure rest directly on outcropping granitoid rock (even if rather irregular), not on a horizontal plane, but in an irregular way following the natural morphological variations of the rocky outcrop (Fig. 7); there are apparently no foundation structures, which otherwise would not have been necessary. The ashlars of the main wall structure are irregularly shaped (Fig. 8), slightly roughhewn in stakes (bundle), with dimensions that vary on average from a minimum of $10 \mathrm{~cm}$ to a maximum of $50 \mathrm{~cm}$ (Figs. 4-8), with a greater frequency between 20 and $30 \mathrm{~cm}$ (Figs. 7, 8). Near the openings (jambs, architraves, etc.) the stone elements are squared at least on two sides (sometimes on 3 sides). Both in the wall structure and in the decorative elements are present stone ashlars of re-use in more recent times, and above all of replacement and integration of rocks in the renovation and restoration of the last ones the decades.

Precisely as a result of the latter, one can observe the repositioning of several ashlars, espe- 
cially in the truncated-conical part facing south, which evidently suffered the greatest damage and degradation due to the exposure to the dominant winds coming from the south, therefore from the neighbour sea (about $20 \mathrm{~m}$ away). In the south side of the tower wall it is easy to observe the restoration interventions with replacement and addition of new ashlars of the same stone (local granitoid rocks), but with smaller dimensions, usually between 6 and $25 \mathrm{~cm}$. This different dimensional aspect is mainly due to the difficulty in replacing entire masonry ashlars belonging to the first phase of the tower installation. In fact, the restoration focused on replacing the more superficial stone elements of the masonry with thicknesses usually not exceeding 25 $\mathrm{cm}$. Unfortunately this intervention is clearly visible, above all due to the decidedly more frequent use of smaller wedge-shaped stone elements ("wedges") with dimensions of about 6-10 $\mathrm{cm}$, that make the wall texture decidedly different from the original one which is instead characterized by a more heterogeneous dimensional variability of the ashlars.

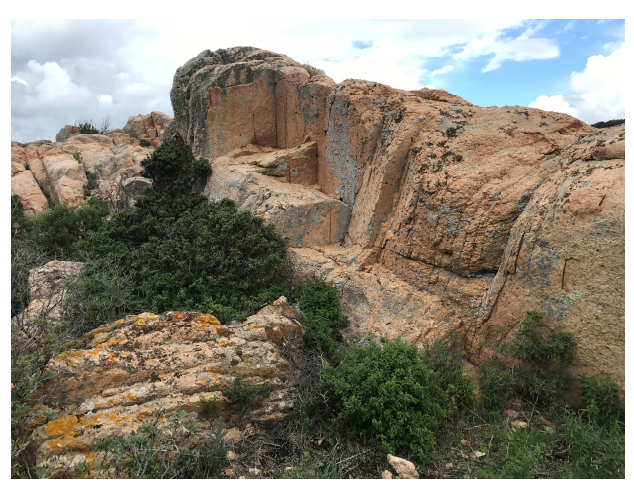

Fig. 9. Quarry granitoid outcrops from which the ashlars used for the tower were extracted.

\subsubsection{Ancient mortars}

The mortars used in the construction of the tower for ease of analysis can be divided into three main functional groups: render (rinzaffo) mortars, bedding (?) mortars of irregular stone ashlars making up the masonry, plaster mortars which cover the masonry (in this study only external plasters are analysed). In the group of plasters we add the restoration mortars used in the restructuring interventions of the last decades, that not studied in this work.

The render mortars are observable only on some sections of the outer portions of the tower outer wall; it was not possible to analyse them indepth inside the masonry, since the original plasters or restoration mortars are present externally. It is assumed that even in depth the actual bedding mortars have the same composition (or at least similar), but undoubtedly a deep sampling will be necessary to define it with certainty. The render mortars, which penetrate between the stone ashlars, are made up of a lime-based binder, and of an aggregate consisting of both mineralogical phases and lithoclasts of various origins. From the grain size point of view (by macroscopic in situ observations), the aggregate has a diameter range generally between 1 and $8 \mathrm{~mm}$, with a frequency greater between 1,5 and $4 \mathrm{~mm}$. The minerals making up the aggregate are mainly represented by quartz and feldspars, while the variety of lithoclasts substantially reflects the lithologies present in the neighbouring outcrops. There are also lithoclasts of different origins, probably referable to lithologies outcropping at a greater distance from the tower area.

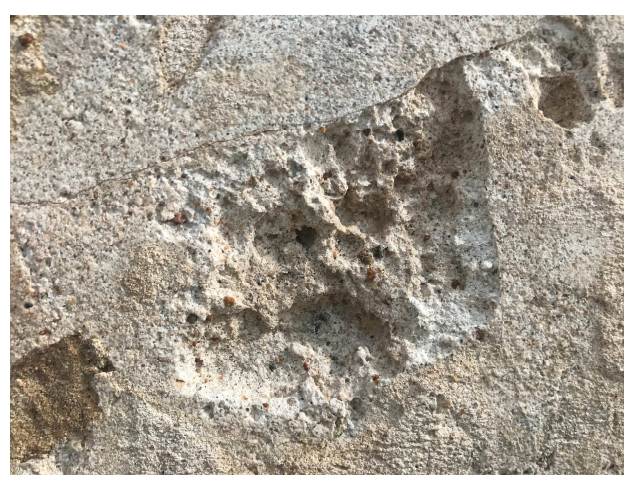

Fig. 10. Plaster mortar from west side of tower wall.

Given the presence of a beach less than $100 \mathrm{~m}$ away from the tower, it is likely that the builders chose the beach sand shore as a source of supply for the aggregate of the mortars. In fact, from a brief macroscopic analysis of the sand sediments of the beach, a certain similarity is evidenced in fact with the aggregate used in the bedding mortars of the tower. This fact would also confirm the presence in the aggregate of rocks not out- 
cropping in the area of the tower and probably coming from the catchment areas behind the beach. A detailed mineralogical and petrographic analysis following sampling of the materials of the tower and the outcrops will be able to describe the above hypothesis better and with certainty.

The original render mortars can be observed mainly in the north side of the tower wall, as they were replaced in most of the remaining sides by restoration mortars, due to the obvious degradation suffered.

The original plaster mortars are present only in the north side of the tower, while in the other sides they are absent and partly replaced by the mortars of periods following the first installation of the tower. From a compositional point of view, there is a similarity with the render mortar and bedding mortars even if we observe a lower grain size of the aggregate used, as indeed good construction technology requires. It is not to be excluded that even this aggregate was taken from the finest fraction of the sand of the beach near the tower.

\section{Conclusions}

From the morphological and architectural point of view, the Budello tower is coherent with the classification called senzillas; this coherence is not only formal but also substantial, as evidenced by the internal structural layout consistent with the projects of the military genius of Spain.

As regard the stones and mortars, although used materials have a good weathering resistance (at least as regards granitoid rocks), there are evident processes of alteration from a chemicalphysical point of view. The degradation (in agreement with Columbu, et al., 2015a; Columbu, Meloni, 2015 for other monumental coastal artifacts) is generated mainly by the agents induced by the proximity of the sea: marine aerosol (mainly with $\mathrm{NaCl}$ salts), solar radiation, dominant winds coming from south-east, south and subordinately south-west. The action of the salts, together with that of other hygroscopic phases occasionally present (e.g. gypsum, clay minerals), through cyclic (sometimes even daily) solubilisation / crystallisation mechanisms, heavily damage the stone and especially mortar microstructure bringing it to strong internal decohesion.

The granitoid rocks with which the stone ashlars were made, having been taken from the most superficial portions of the rocky outcrop, showed, already at the time of their installation in the tower, an evident state of degradation (observable even in the extraction fronts), deriving from the weathering and geological processes that lasted for some hundreds of millions of years, following their petrogenesis occurred in the Paleozoic. For these reasons, these rocks, once laid in the structure, have undergone a further increase in degradation, which has led, in the case of already severely decayed stone, to a rounding of the angularity of the ashlars.

As for the other sedimentary lithologies (sandstones, calcarenites, etc.), used to make occasional ashlars (in general of small size), we observe a greater degradation, induced also by the dissolution of the carbonate cement, with evident decohesion of the matrix and consequent disgregation of the stone.

The mortars, being located in the most superficial part of the masonry, show evident and advanced stages of alteration, in which fano- and sub-efflorescence are often found. As already discussed above, following the degradation of the tower, the plaster mortars were removed from the wall surface, especially in the south side of the tower, where the masonry was then replaced and restored with the integration of new stone ashlars similar to the original rock (but generally with a smaller size) and with the addition of a restoration mortar of dubious composition.

The original plasters, where still preserved, show however evident chemical-physical alteration represented by an increase in the surface porosity induced by the dissolution of the lime-based binder, probable also sulphation (with formation of gypsum) and, from a physical point of view, the presence of typical degradation processes, such as exfoliation and flaking. 
The render and bedding mortars were heavily degraded on the south side of the tower up to a depth of 5-10 cm from the original external profile of the tower (later integrated with mortars and stone ashlars being restored), while in some zones of the north side can still be observed, albeit partly covered by plaster mortars.

\section{Bibliography}

Columbu, S.; Carcangiu, G.; Sitzia, F. (2015a). "The ancient mortars and geomaterials of tower fortification of Nora (Pula, Sardinia, Italy)”, in Rodriguez Navarro, p., ed., FORTMED 2015, Universitat Politècnica de València Ed., València, vol. II, pp. 357-363

Columbu, S.; Cazzani, A.; Ruggieri, A. (2015b). Relations between static-structural aspects, construction phases and building materials of San Saturnino Basilica (Cagliari, Italy)", in CHNT 19, 2014 - Proceedings of the 19th International Conference on Cultural Heritage and New Technologies. Wien (Austria), 3-5 november 2014, Museen der Stadt Wien - Stadtarchäologie, pp. 1-15.

Columbu, S.; Meloni, P. (2015). "Alteration processes of geomaterials used on the pentagonal tower of Serravalle Castle (central-west Sardinia, Italy)", in in Rodriguez Navarro, p., ed., FORTMED 2015, Universitat Politècnica de València Ed., València, vol. II, pp. 373-380.

Fois, F. (1981). Torri spagnole e forti piemontesi in Sardegna, La Voce Sarda, Cagliari.

Guidetti, M. (1989). Storia dei Sardi e della Sardegna: L'età moderna, dagli Aragonesi alla fine del dominio spagnolo, Editoriale Jaca Book, Milano.

Mele, G. (2000). Torri e cannoni. La difesa costiera in Sardegna nell'età moderna, Edes, Sassari.

Montaldo, G. (1992). Le torri costiere in Sardegna, Carlo Delfino, Sassari.

Montaldo, G. (1999). "Forti e torri costiere", in Le architetture fortificate della Sardegna centro-meridionale. Atti della giornata di studio, Cagliari, 16 October 1999.

Pillosu, E. (1957). Le torri litoranee in Sardegna, Tipografia La Cartotecnica, Cagliari.

Pillosu, E. (1959). "Un inedito rapporto cinquecentesco sulla difesa costiera di Marco Antonio Camos", in Nuovo bullettino bibliografico sardo e archivio delle tradizioni popolari, Cagliari.

Rassu, M. (2000). Guida alle torri e forti costieri della Sardegna, Artigianarte, Cagliari.

Rassu, M. (2005). Sentinelle del mare. Le torri della difesa costiera della Sardegna, Grafica del Parteolla, Cagliari.

Russo, F. (1992). La difesa costiera del Regno di Sardegna dal XVI al XIX secolo, Stato maggiore dell'Esercito, ufficio storico, Roma.

Vacca, D. (2006). La strategia difensiva dei sovrani spagnoli nel Regno di Sardegna e nel Mediterraneo tra il 16 e il 17 secolo: difesa statica e difesa dinamica, Dottorato di Ricerca in Storia Moderna e Contemporanea, Anatra, B., coord., Murgia, G., tr., Cagliari. 